\title{
A Novel In Situ Self-Dissolving Needle Web Based on Medicated Cellulose Hollow Fibres with Drug Delivery Features
}

\author{
Dirk Hoefer $^{1} *$, Gregor Hohn ${ }^{1}$, Nadja Berner-Dannenmann ${ }^{1}$, Thomas Schulze ${ }^{2}$, Frank-Günther \\ Niemz ${ }^{2}$, Timo R. Hammer ${ }^{1}$ \\ ${ }^{1}$ Hohenstein Institutes, Schlosssteige 1, 74357 Boennigheim, Germany \\ ${ }^{2}$ Thueringisches Institut fuer Textil- und Kunststoff-Forschung e.V., Breitscheidstrasse 97, 07407 Rudolstadt, Germany
}

\begin{abstract}
Medicated wound dressings incorporate chemicals which have therapeutic value. The objective of this study was to investigate the in vitro model drug release from a biodegradable needle web, based on medicated cellulosic hollow fibres, which self-dissolve in the presence of aqueous solutions.

Cellulose hollow fibres were prepared by a standard dry-wet phase inversion spinning process. Dressings were made using established techniques in the nonwoven industry. Two sets of hollow fibres were filled with different drug solutions: One set contained the enzyme cellulase and the second set was filled with either antibacterial Pseudomonas aeruginosaspecific bacteriophages, or the wound debriding enzyme Krillase ${ }^{\circledR}$. Both fibre sets were freeze-dried to (i) inactivate the spontaneous biodegradation of the fibres by cellulase and (ii) to preserve the wound healing activities of the biotherapeutic model drugs. Needle webs containing different mixing ratios of the two sets of hollow fibres were made. Whereas bacteriophages were released after rewetting the webs in in-vitro experiments with high burst effect, Krillase ${ }^{\circledR}$ showed a sustained drug release over $20 \mathrm{~h}$, which was found to be dependent on the mixing ratio of cellulase versus Krillase ${ }^{\circledR}$-hollow fibres. Possible release mechanisms and therapeutic benefits are discussed.
\end{abstract}

In summary, needle webs of medicated cellulosic hollow fibres are a new self-dissolving drug delivery system.

Keywords: Bacteriophages, Biotherapy, Cellulase, Chronic wounds, Krillase ${ }^{\circledR}$, Viscose, Wound dressing.

\section{INTRODUCTION}

Successful treatment of chronic or complex wounds depends on the hygienic state of the wound, properly performed wound bed preparation, the condition of the individual patient and the therapist's experience which leads to the choice of adequate wound dressings. Thus, clinicians have to consider a variety of aspects when choosing the correct dressing [1]. Acute wounds, which usually heal completely within 8-12 weeks [2] set lower levels of obligations on dressings than chronic wounds, that need more than 12 weeks for healing and often reoccur [3]. This is because in chronic wounds, healing is impaired due to repeated tissue insults or physiological conditions of the patient such as diabetes, malignancies or persistent infections [4]. Moreover, these recalcitrant wounds require frequent removal of dressings for rinsing/disinfection measures to combat infections or to arrange proper wound bed preparation. The complexity of wounds and wound healing processes therefore place high demands on modern wound dressings. Basic criteria for dressings have already been described by Winter [5] and Turner [6] like biocompatibility, prevention of wound dehydration, retaining a favourable moist environment, physically

*Address correspondence to this author at the Hohenstein Institutes Schlosssteige 1, 74357 Boennigheim, Germany; Tel: +4971 43271 432; Fax: +4971 43271 94432;

E-mail: d.hoefer@hohenstein.de protecting the wound against dust and bacteria, allowing gas exchange and promoting epithelisation, but also the provision of a thermal insulation, low adherence, the absorption of blood and exudate as well as cost effectiveness are required [7].

However, in chronic non-healing wounds, healing may additionally be promoted by delivering therapeutic agents via controlled drug delivery in order to manage appropriate exudate management, infection control and proper wound bed preparation [8]. Given the aging population, the growing number of complex wounds and the increase in multi-drug resistant infections, an improvement in wound healing is a central issue in healthcare. Therefore, drug delivery was announced to be one of the keys for advanced wound care [9]. The multitude of modern wound dressings with drug delivery features are based on hydrocolloids (e.g. carboxymethylcellulose), biopolymers (e.g. alginate), hydrogels (synthetic polymers, e.g. polymethacrylates, polyvinylpyrrolidine), polyurethane foams/films or silicone gels $[9,10]$. Drugs usually are incorporated either into nanostructures [11], microcapsules [12], the hydrogel matrix [13] or integrated into fibrous structures during the process of fibre spinning. Besides the basic polymers or drug incorporating techniques of medicated dressings, their mutual challenge is to omit a rapid discharge of the endowed drugs. This phenomenon, called early burst release, leads to drug overdose and problems of toxicity, whereas the stage of slower drug release may be below the drug's therapeutic dosage range. Therefore, medi- 
cated dressings ideally deliver a nearly instantaneous initial dosage of the drug at the optimum therapeutic concentration, followed by a sustained constant delivery rate (i.e. zero-order kinetics) that maintains the local concentration at the optimum dosage level for as many days as necessary to achieve complete and effective wound healing [14].

To overcome the drawbacks of medicated wound dressings with regard to rapid drug discharge, we addressed in this study a new concept of a wound dressing system which uses the advantages of biodegradability to regulate the drug delivery profile. In order to obtain biodegradability and drug delivery features, viscose hollow fibres (capillary membranes) were endowed with inactivated, lyophilized drugs and subsequently functionalized into a medicated needle web by standardized manufacturing methods. We thought to control biodegradation by using a second set of cellulase-filled hollow fibres, to start an intrinsic self-dissolving process. For the characterization of drug delivery features we used two biotherapeutic model drugs: Krillase ${ }^{\circledR}$ and Pseudomonas aeruginosa-specific bacteriophages. Krillase ${ }^{\circledR}$, a protease of antarctic krill (Euphasia superba) possesses tissue-digesting properties and therefore has promising therapeutic potential with respect to debridement of necrotic ulcerations $[15,16]$. Bacteriophages were chosen for their antibacterial potential and as an alternative to antibiotics [17]. By using these model drugs we were able to characterize the interaction of the hollow fibre system with functional proteins (i.e. Kril$\operatorname{lase}^{\circledR}$ ) and larger active particles (i.e. bacteriophages) and to study their release after re-wetting.

\section{MATERIALS AND METHODOLOGY}

\section{Synthesis of Cellulosic Hollow Fibres}

Cellulosic hollow fibres were spun from high viscous spinnable dopes consisting of microcrystalline cellulose powder (Accent Microcell Industries, Ahmedabad, India) dissolved in N-methyl morpholine N-oxide (NMMO) monohydrate on a spinning machine. In brief, $10 \%$ cellulose solutions were extruded at $88^{\circ} \mathrm{C}$ through circular-slit spinnerets at a take-up velocity of $45 \mathrm{~m} \mathrm{~min}^{-1}$. Simultaneously, an internal NMMO core fluid at a concentration of $60 \mathrm{wt} .-\%$ was injected straight into the fibre in order to establish the void cavity. The extrudate was then promoted into a coagulation bath $\left(20^{\circ} \mathrm{C}, 10\right.$ wt.- $\left.\%\right)$ with $5 \mathrm{~cm}$ distance spinneret/coagulation bath to expand and to keep away walls from collapsing.

After spinning the freshly spun gel fibre bundles were extracted five times, before they were treated with an aqueous liquor containing $10 \mathrm{wt}$ - $\%$ glycerol for $10 \mathrm{~min}$. Depending on dope properties and bath concentration, the extruded fibres were stretched in an air gap prior to final coagulation and then washed in another aqueous bath. Adjusting the process set values allowed to vary parameters like fineness, internal diameter, wall thickness and pore structure of the hollow fibres in order to affect drug uptake and release properties. After draining of surplus liquor, bundles were dried in a cabinet dryer for $24 \mathrm{~h}$ at $50^{\circ} \mathrm{C}$. Finally, they were reconditioned for $24 \mathrm{~h}$ at ambient temperature and $60 \%$ relative humidity. Fibres obtained in this way were ready for doping with Krillase ${ }^{\circledR}$ or bacteriophages, respectively.

\section{Model Agents Preparation: Krillase ${ }^{\circledR}$ and LKA1-Like Bacteriophages}

A Pseudomonas aeruginosa-specific bacteriophage was isolated from hospital waste water according to Kutter [18]. In brief, 11 of sewage was centrifuged at $1500 \mathrm{x} \mathrm{g}$ for 20 min and the supernatant was mixed with $1 / 10$ volume of 10 fold concentrated CASO-Bouillon. Subsequently the host bacteria were added as wash-out of a fresh agar culture. In this study, phages were propagated in the host strain ATCC 27853 of Pseudomonas aeruginosa (DSMZ, German Resource Centre for Biological Material, Braunschweig, Germany), which was cultivated according to the protocols of the supplier. The phages were not further classified by genomic or other analysis. Since the bacteriophage used in this study most likely resembled the Pseudomonas aeruginosa phage LKA1, originally described by Ceyssens et al., [19], it was termed LKA1-like phage (abbreviated: LLP). The protocols allowed the cultivation of LLP to a final concentration of $10^{11}$ plaque forming units ( $\mathrm{pfu}$ ) $\mathrm{ml}^{-1}$. The initial concentration of a stock solution of LLP prior to lyophilization in hollow fibres was $10^{10} \mathrm{pfu} \mathrm{\textrm {ml } ^ { - 1 }}$. For the detection of LLP, nonlysed bacteria cells were separated by centrifugation $(5 \mathrm{~min}$, $2600 \mathrm{xg}$ ) and by sterile filtration. Phage titre was determined by dilution series in phage buffer $(10 \mathrm{mM}$ Tris $\mathrm{pH} 7.54,10$ $\mathrm{mM} \mathrm{MgCl} 2,10 \mathrm{mM} \mathrm{NaCl}$ ). $3 \mathrm{ml}$ of slurry agar (TS broth with $6.5 \mathrm{~g} \mathrm{l}^{-1}$ agar) were inoculated with $200 \mu \mathrm{l}$ of an overnight culture from $P$. aeruginosa and $100 \mu \mathrm{l}$ of each phage dilution and then plated on a TS agar plate. After incubation for 18 hours at $37^{\circ} \mathrm{C}$ pfu were counted.

The enzyme Krillase ${ }^{\circledR}$ was a kind gift of Prof. Jan Vincent (Arcimboldo, Stockholm, Sweden), that had been purified from antarctic krill Euphausia superba. The initial concentration of the Krillase ${ }^{\circledR}$ stock solution prior to filling the hollow fibres was $30 \mathrm{U} \mathrm{ml}^{-1}$. The synthetic colorimetric substrate $\mathrm{N}$ - $\alpha$-benzoyl-D, L-arginine-p-nitroanilide hydrochloride (BApNA) (Fluka, Germany), was used to determine the tryptic activity of Krillase ${ }^{\circledR}$ extracts based on the method of Erlanger et al., [20]. $100 \mu \mathrm{l}$ of Krillase ${ }^{\circledR}$ extract from the doped needle webs were added to $900 \mu 1$ of BAPNA solution ( $0.5 \mathrm{mM}$ in PBS) and measured every 5 min over 15 cycles. Total enzymatic activity of extracts was monitored using a spectrophotometer (Tecan Genios Reader, Crailsheim, Germany). Reaction rates were determined at $25^{\circ} \mathrm{C}$ from linear portions of the absorption at $405 \mathrm{~nm}$ wavelength $\left(\mathrm{A}_{405 \mathrm{~nm}}\right)$ versus time plots using the extinction coefficient $\varepsilon_{405 \mathrm{~nm}}=$ $8800 \mathrm{M}^{-1} \mathrm{~cm}^{-1}$ and assuming steady-state conditions. All reaction mixtures contained $1 \mathrm{mM}$ BApNA, $500 \mu \mathrm{l}$ phosphate-buffered saline (PBS), and $5 \mu$ l Krillase ${ }^{\circledR}$ stock solutions, or $40 \mu \mathrm{l}$ of dissolution fluid of cellulase-dissolved hollow fibres as well as distilled water to reach a final volume of $1 \mathrm{ml}$. One unit of enzyme activity was defined as $1 \mu \mathrm{mol}$ of p-nitroaniline produced per minute.

\section{Doping of Hollow Fibres and Freeze-Drying}

A bunch of approximately 100 hollow fibres were parallelized and placed with their tips into beakers containing the respective stock solutions to avoid adhesion of drugs along the outer side of the fibres. The fibres filled themselves up to $10 \mathrm{~cm}$ in height by capillary forces. Subsequently, fibres were unscrambled and either dried at room temperature or freeze-dried. For freeze-drying, either $10 \%$ of saccharose, 
Table 1. Dimensions and Textile-Physical Data of Three Batches (\#) of Hollow Fibres

\begin{tabular}{|c|c|c|c|c|}
\hline Test Parameter & Unit & \# 569/5 & $\#$ 570/3 & \# 585 \\
\hline External diameter & $\mu \mathrm{m}$ & 395 & 320 & 315 \\
\hline Internal diameter & $\mu \mathrm{m}$ & 319 & 253 & 240 \\
\hline Wall thickness & $\mu \mathrm{m}$ & 38 & 33,5 & 37.5 \\
\hline Linear mass density & dtex & 390 & 271 & 309 \\
\hline Tensile strength & $\mathrm{cN}$ & 63.2 & 61.5 & 51.8 \\
\hline $\begin{array}{l}\text { Coefficient of variation } \\
\text { (Tensile strength) }\end{array}$ & $\%$ & 10.6 & 10.6 & 15.8 \\
\hline Elongation, dry & $\%$ & 37.2 & 28.9 & 32.6 \\
\hline Elongation, wet & $\%$ & 25.8 & 21.7 & 19.5 \\
\hline Tenacity, dry & $\mathrm{cN} / \mathrm{tex}$ & 1.62 & 2.26 & 1.69 \\
\hline Tenacity, wet & $\mathrm{cN} / \mathrm{tex}$ & 0.67 & 1.03 & 0.67 \\
\hline
\end{tabular}

betain or milk powder were added to the stock solutions to stabilize the enzyme/phage activities, respectively. Fibres were then subjected to 0.6 mbar vacuum, freeze-dried at $25^{\circ} \mathrm{C}$ for $48 \mathrm{~h}$ in a freeze-drying device (Christ, Alpha 14LSC, Germany) and finally used for the production of needle webs, as described below. Another set of hollow fibres was filled accordingly with the enzyme cellulase (SigmaAldrich, München, Germany) at a concentration of $5 \mathrm{U} \mathrm{ml}^{-1}$ and freeze-dried immediately after filling.

\section{Preparation of Needle Webs and In Vitro Drug Release Studies}

Two sets of hollow fibres were filled. The first set was doped with the enzyme cellulase, the second set with stock solutions of either the model drugs Krillase ${ }^{\circledR}$ or LLP. Different mixing ratios of the two sets of hollow fibres were then needle-punched on a polyester (PES) support web. The PES binding fibre had a linear mass density of 3.3 dtex. The following machines were used: laboratory carding machine (Memminger-IRO GmbH, Dornstetten, Germany) for mechanical web formation having a nominal width of $600 \mathrm{~mm}$, a web laying apparatus of $600 \mathrm{~mm}$ nominal width (Oskar Dilo Maschinenfabrik KG, Eberbach, Germany) equipped with upright lattice and transverse laying for top stitch condensation with two needle beds each 25 needles per $\mathrm{cm}^{2}$. Needle webs containing mixing ratios of $2: 1,1: 1,1: 2$, and $1: 3$ of drug-filled fibres versus cellulase-filled fibres were subjected to physiological saline PBS and incubated at room temperature for $30 \mathrm{~min}$ up to $20 \mathrm{~h}$ before measuring the drug release of Krillase ${ }^{\circledR}$ or bacteriophages, respectively. For preservation experiments stock solutions of LLP were transferred by capillary forces into cellulosic hollow fibres, freeze-dried and processed into needle webs. Four weeks later, the webs were rewetted in physiological saline. In these experiments the dissolution fluids were subjected to filmed grids and observed by transmission electron microscopy as described below in order to evaluate the integrity of the phages in detail.

\section{Electron Microscopy}

Freshly spun hollow fibres and PBS-exposed needle webs were dehydrated in an increasing series of ethanol solutions (70-100\%). Subsequently, they were dried, mounted on metal stubs, covered with an Ion Sputter SCD/040 in- strument for examination and analyzed with a scanning electron microscope (Jeol JSM 6100, Jeol Ltd., Tokio, Japan) set at 5 and $10 \mathrm{kV}$. Phage solutions of LLP and solutions of freshly cellulase-dissolved hollow fibres containing LLP, which had been stored for 4 months at room temperature, were spotted on filmed grids, contrasted by uranyl acetate and viewed with a transmission electron microscope at 80 kV (EM 10, Zeiss, Germany).

\section{RESULTS}

\section{Synthesis and Characterization of Hollow Fibre Needle} Webs

Cellulosic hollow fibres were prepared according to the ALCERU-process from a special dissolving pulp with a low degree of polymerisation (DP) by means of dry-wetspinning. A low DP-value was chosen to ensure a temporarily prolonged cellulase-driven dissolution of the fibres, in order to prevent a burst release of active substances stored in the hollow fibre void cavity. Table 1 shows the dimensions and textile-physical data of three batches of hollow fibres as typically obtained by spinning a dope of moderate viscosity and using a given shaping tool design.

The external diameters exceeded that of solid cellulose fibres several times (Fig. 1a). Since the hollow fibres were too fragile to be further processed by usual weaving or knitting textile technologies, we produced needle-punched nonwovens in combination with a PES support web (Fig. 1b). The PES-support web showed a weight per unit area of $45 \mathrm{~g}$ $\mathrm{m}^{-2}$. It was blended in mass ratios of 1 (PES support web) : 1.7 (cellulase-filled hollow fibres) : 0.67 (LLP- or Krillase ${ }^{\circledR}$ containing fibres, respectively), corresponding to weight ratios of 29,85:50,15:20,00 wt.-\%. The total area weight of the needle web was $430 \mathrm{~g} \mathrm{~m}^{-2}$, which resulted in a needle web representing the prototype for a drug eluting wound dressing inlay. For dissolution experiments, the web was moistened with physiological saline. After rewetting the fibres for $24 \mathrm{~h}$, webs were subjected to scanning electron microscopy. The drug and cellulase-containing fibres were largely degraded due to the reactivation of cellulase, whereas the PES support web remained completely unaffected (Fig. 1c, d). Control webs without cellulase-fibres were used as a control. In such cases, no fibre-dissolution was observed. 

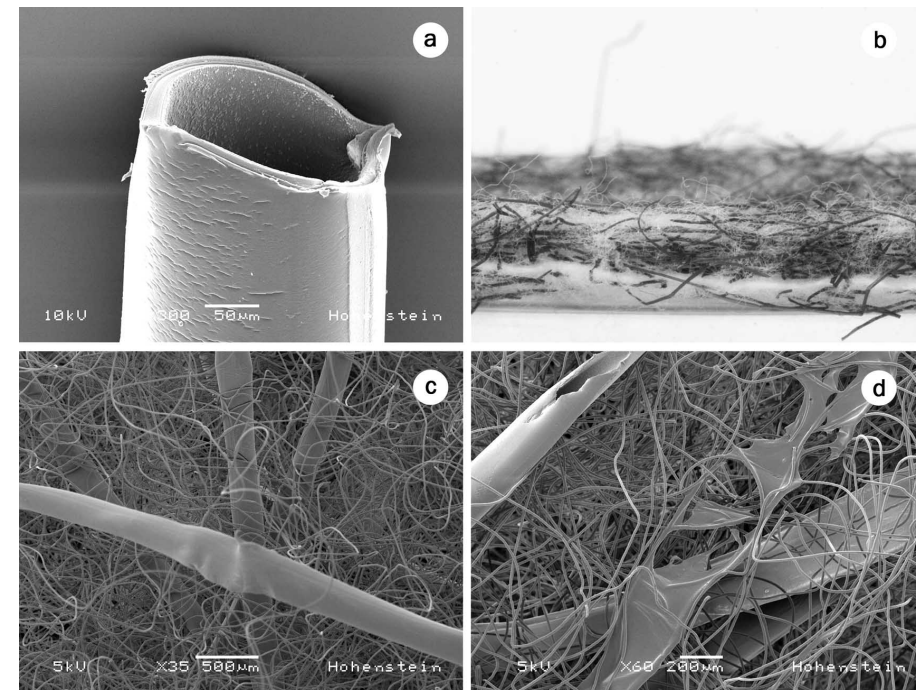

Fig. (1). Representative scanning electron (a) and stereo-microscope images (b) of cellulosic hollow fibres and medicated needle webs. The hollow fibres displayed solid walls of constant thickness (a). The stereomicroscope view offers details of a dense layer of drug-filled (dark) hollow fibres needled onto a supporting web of brighter PES fibres at $10 \mathrm{x}$ magnification. Moisture induced dissolution of drug-filled hollow fibres is shown in (d), whereas (c) shows intact hollow fibres at dry conditions.
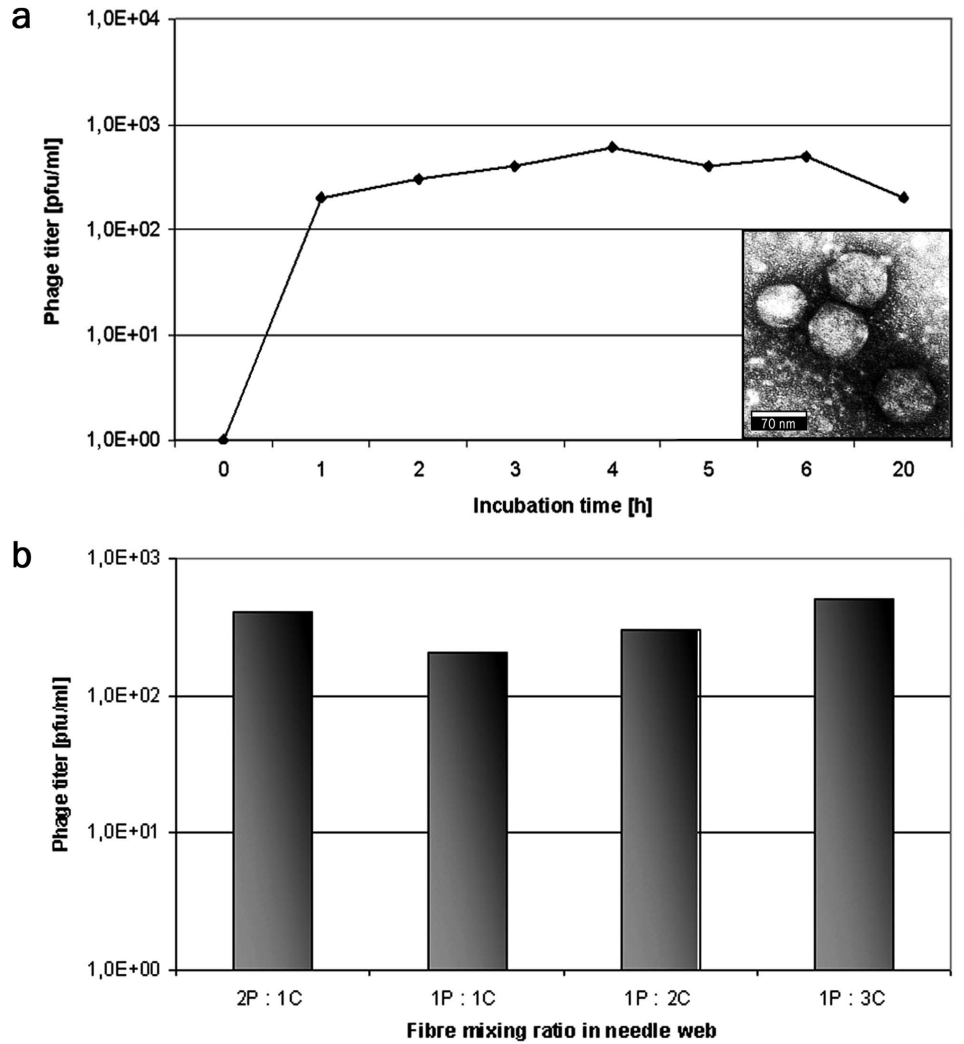

Fig. (2). Phage release studies from different needle webs showing high burst release of phages within the first hour after rewetting (a). Insert shows reactivated Pseudomonas-specific phages (LLP) with intact morphology. Increasing the ratio of cellulase-fibres in the nonwovens did not result in higher phage titers as shown by plaque assays $(\mathbf{b}) . \mathrm{P}=$ phage-filled fibres, $\mathrm{C}=$ cellulase-filled fibres.

\section{Phage Preservation Experiments and In Vitro Release Studies}

The integrity and morphology of LKA1-like bacteriophages (LLP) was not affected either by freeze-drying or storage (Fig. 2a, insert). To precisely evaluate their infectivity, we ran in vitro drug release studies with plaque assays and LLP-containing needle webs in the ratio $2 \mathrm{P}: 1 \mathrm{C}$ (2 parts phage fibres versus 1 part cellulase-fibres). Plaque assays also showed that LLP were still contagious to their host $P$. aeruginosa, further indicating that these phages can successfully be reactivated and preserved over at least 4 weeks. The release kinetics for phages was observed over a time frame of $20 \mathrm{~h}$. Fig. (2a) shows the release profile of LLP from needle webs. We detected a high burst effect with most of the phages being released from the web within the first hour after rewetting. 


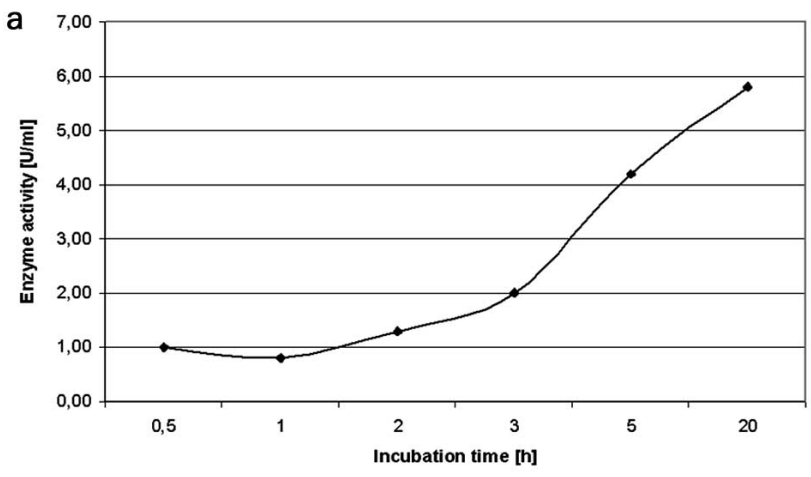

b

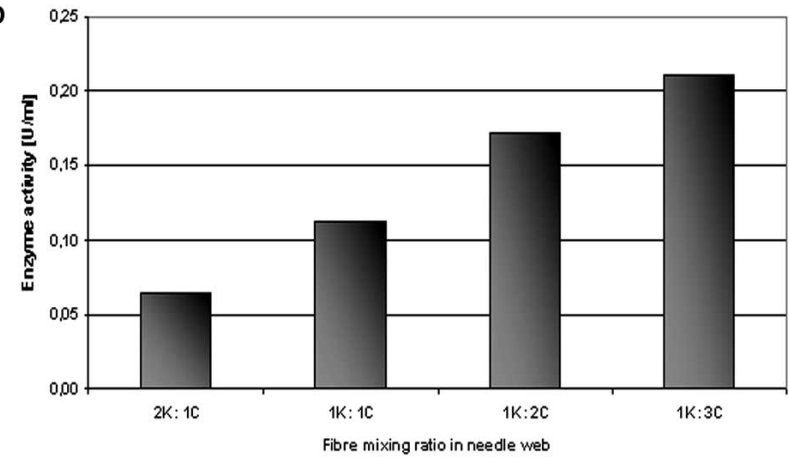

Fig. (3). Krillase ${ }^{\circledR}$ release studies from different needle webs. Enzyme activity showed a release of Krillase ${ }^{\circledR}$ starting after a lagphase of $3 \mathrm{~h}$ and a continuous increase up to $20 \mathrm{~h}$ (a). Increasing the ratio of cellulase-fibres in the nonwovens resulted in enhanced tryptic activities of the reactivated and released enzyme (b). Thus, the increase in cellulase-fibres was capable of releasing the entrapped Krillase ${ }^{\circledR}$ out of its compartment. $K=$ Krillase $^{\circledR}$-filled fibres, $\mathrm{C}=$ cellulase-filled fibres.

In another experiment, four different needle webs were manufactured, each of which contained a different mixing ratio of phage-containing fibres versus cellulase-fibres, namely $2 \mathrm{P}: 1 \mathrm{C}$ (2 parts phage fibres versus 1 part cellulasefibres), 1P:1C, 1P:2C and 1P:3C (Fig. 2b). In these release experiments, we were unable to show that increasing the ratio of cellulase-containing fibres in the nonwoven webs resulted in increased phage activity.

\section{Krillase $^{\circledR}$ Preservation Experiments and In Vitro Release Studies}

Stock solutions of Krillase ${ }^{\circledR}$ were transferred into another set of cellulosic hollow fibres, freeze-dried, mixed with cellulase-filled fibres and subsequently processed as described to obtain Krillase ${ }^{\circledR}$-containing needle webs. After four weeks of incubation at $4{ }^{\circ} \mathrm{C}$ needle webs were rewetted in physiological saline and the released enzyme-activity (i.e. tryptic activity for Krillase $^{\circledR}$ ) was specifically detected by the BApNA assay over a time period of $20 \mathrm{~h}$ (Fig. 3a). Drug release was evaluated by plotting enzyme activity versus time. In contrast to phage-release, no burst effect was observed in kinetic experiments with Krillase $^{\circledR}$-containing webs. Instead, after a short initial lag-phase of $3 \mathrm{~h}$, we observed a continuous increase in enzyme activity up to $20 \mathrm{~h}$. The amount of active ingredient released from the hollow fibre web showed time dependence with the highest activity reached after $20 \mathrm{~h}$, with nearly $6 \mathrm{U} \mathrm{ml}^{-1}$. The same enzyme activity was reached, when the dressings were subjected to human wound exudate that was pooled from six chronic wound patients (data not shown). Hence, Krillase ${ }^{\circledR}$ was also successfully entrapped and preserved in cellulosic hollow fibres as confirmed by enzyme activity experiments.

To further document the regulatory effect of the cellulase-fibres on the delivery profile within the web, we started another approach. Four different needle webs were produced, each of which containing a different mixing ratio of Krillase ${ }^{\circledR}$ fibres versus cellulase-containing fibres, namely $2 \mathrm{~K}: 1 \mathrm{C}$ (2 parts Krillase $^{\circledR}$ fibres versus 1 part cellulase-fibres), $1 \mathrm{~K}: 1 \mathrm{C}, 1 \mathrm{~K}: 2 \mathrm{C}$ as well as $1 \mathrm{~K}: 3 \mathrm{C}$. In these experiments a diluted stock solution of Krillase ${ }^{\circledR}$ with minor enzyme activity was used. Fig. (3b) summarizes the results. In these experiments we observed, that increasing the ratio of cellulasefibres in the nonwoven webs resulted in an increased tryptic activity for the released enzyme Krillase $^{\circledR}$, most probably due to a faster fibre dissolution and enzyme release. Thus, the increase in cellulase-fibres was capable of releasing the entrapped Krillase ${ }^{\circledR}$ out of its reservoir compartment.

\section{DISCUSSION}

Today, the most common way to deliver topical pharmaceutical agents to wounds is via solutions, creams or ointments. But recently, a new generation of medicated dressings for drug delivery has been developed with the incorporated drugs playing an active role in the wound healing process. For this purpose, antimicrobials [14, 21-25], growth factors $[26,27]$, or other active compounds such as vitamins and mineral supplements [28] are integrated into dressings made for example of hydrocolloids, hydrogels, alginates, polyurethane or silicone [9]. Medicated wound dressings often have limitations with regard to rapid drug discharge. Blanchemain and colleagues, for example, enclosed a hydrophilic drug into hydrophobic materials in order to delay water penetration and subsequent drug release [29]. In another approach drug adherence to the carrying matrix was enhanced [30].

To overcome the problem of a burst release, we therefore addressed in this study a new concept of a drug-eluting wound dressing which uses the advantages of enzymatic biodegradability to regulate drug release. Many other groups currently use modern electrospinning techniques to spin drug-eluting fibres out of biodegradable biopolymers, like silk or poly(e)-caprolactone. These nanofibres contain for example growth factors [26] or nanoparticles [31]. In contrast to these rather complex techniques, we used a standardized fibre spinning process to produce viscose hollow fibres (capillary membranes), as typically used for many plasmapheresis applications, with variable diameter and wall thickness. In this respect our research approach was application-oriented, since it relies on established techniques in textile industry, that can easily be scaled up [32]. Textilephysical data of hollow fibres show, that their tensile strength and elasticity were insufficient to be processed into a woven or knitted fabric, since their external diameters exceeded that of typical textile fibres several times. Nevertheless, the fragile fibres, which were filled with lyophilized model drugs prior to fabric processing, could be successfully needle-punched onto a supporting basis web of a PES nonwoven, thus forming a medicated dressing. 
By the end of the 1980s, heparinase was immobilized within cellulosic hollow fibres to remove heparin's anticoagulant activity in blood filters [33-35]. Our fibres were endowed by simple capillary forces with two biotherapeutic model drugs that were not immobilized, but subsequently freeze-dried: The debriding enzyme Krillase ${ }^{\circledR}$, a protease of the antarctic krill (Euphasia superba) and antibiotic bacteriophages. Krillase ${ }^{\circledR}$ possesses strong tissue-digesting properties due to an unspecific multi-enzyme complex of trypticlike enzymes which has promising therapeutic potential with respect to debridement of necrotic ulcerations $[15,16]$ and has been shown to be useful to combat dental placque biofilms [36]. Bacteriophages were chosen for their antibacterial potential and as an alternative to antibiotics [17, 37]. It is widely purported that phages can not be lyophilized [18]. Surprisingly, using betain, milk powder or saccharose as stabilizers, LLP phages could easily be lyophilized in our hands, stored up for several weeks in hollow fibres and were successfully reactivated as confirmed by functional and morphology assays. Recently, we were able to show that other proteins as well as antibiotics can also be bound and released with the cellulosic hollow fibres [38]. The binding properties of our model drugs along the fibres thus can be assumed to depend mostly on size and charge of the particles/enzymes.

We were able to control the biodegradation of the nonwoven upper layer by using a second set of hollow fibres filled with the enzyme cellulase, to start an intrinsic selfdissolving process which sets in after re-wetting the needleweb. It has been demonstrated here using Krillase ${ }^{\circledR}$-filled hollow fibres, that the ratio of the two sets of hollow fibres can be tuned to achieve controlled release of drugs approaching time-independent, zero-order kinetics. This, together with the upscaling possibilities mentioned above, represents an important advance in the development of fully degradable wound dressings, capable of delivering a broad range of therapeutic agents. This effect can be explained by the highly porous network structure of the inner hollow fibre wall, which does not only store substances on drying, but regains release abilities when remoistened. The release kinetics of the drugs from the dissolving fibres are dependent upon a number of factors, like water influx, drug dissolution, drug loading in the hollow fibres and drug binding onto the porous network structure of the inner wall surface. These parameters have also been described to be responsible for drug release in other drug delivery dressings [39-44].

It is tempting to speculate on possible therapeutic benefits of the medicated hollow fibre wound dressing, keeping in mind, that the optimal drug release kinetics strongly depends on the desired effect, i.e. instantaneous antibiosis of infected wounds or wound bed preparation. Our data show that bacteriophages, which represent nanoparticles of $\sim 70$ $\mathrm{nm}$, were released from the web rapidly after remoistening. In addition, increasing the rate of cellulase-containing fibres did not significantly alter phage release. These results imply that the particles are stored in the hollow fibres during freeze-drying but do not adhere to the inner fibre wall. Most likely, the phages are dissolved in the liquid immediately and thus released during the first hour. Although we were unable to prevent burst release for phages, most probably due to their particle size, this faster drug delivery profile may be desirable, especially in case of an antibiotic therapy of wound infections [45]. This may be of advantage over the multitude of silver endowed wound dressings for infection control [9]. The number of bioaccessible active silver ions however depends on their interaction with wound exudate components. In our study, bacteriophages were shown to remain active in collected human wound exudate of chronic wound patients and are able to spread throughout the wound area (data not shown).

In contrast to the bacteriophages, the release profile of Krillase $^{\circledR}$ did not show an initial burst, but a constant increase of enzyme activity between $2 \mathrm{~h}$ and $20 \mathrm{~h}$ after rewetting. The ratio of Krillase ${ }^{\circledR}$-containing hollow fibres to cellulase-containing fibres significantly affected proteolytic enzyme activity obtained from the needle web. Enzyme activity increased with raising the proportion of cellulase-containing hollow fibres in the web which implies that the enzyme was bound to the fibre wall and not released until cellulasedriven dissolution of hollow fibres started. For the enzymebased debridement of wounds, this continuous release profile with constant enzyme supply is advantageous as necrotic tissue is degraded continuously. Beside $\operatorname{Krillase}^{\circledR}[15,46]$, the hollow fibre technique presented here would also be favourable for other approaches of enzymatic debridement like streptokinase/streptodornase [47], debrase/debridase [48], collagenase [49] or new plant-derived enzymes [50]. It is likely that the listed debriding enzymes interact in a similar way with the inner walls of cellulosic hollow fibres as the Krill enzyme Krillase ${ }^{\circledR}$. Hence, storage of these ingredients by freeze-drying would favourably allow not only long-term availability of the active debriding principle at the wound surface, but also drug-delivery without further chemical preservatives. The technique presented here is advantageous compared to soaking dressings with drugs [47] or applying raw natural substances [50] with regard to the production of dressings and their bed-side application and thus holds the potential to improve active wound therapy by a ready-to-use wound dressing.

On the basis of our promising results with the debriding enzyme Krillase ${ }^{\circledR}$, we assume, that especially issues of wound healing, like the TIME-concept of proper wound bed preparation could be addressed with our medicated wound dressing in the near future, to accelerate endogenous healing or to enhance the effectiveness of other therapeutic approaches [51]. In order to achieve the desired debridement effect, enzyme activity must not be affected by interaction with the wound environment or other compounds of the wound dressing itself. Recently, Shi et al., showed decreased activity of debriding enzymes of more than $50 \%$ if they were applied together with other active substances like silver or iodine [52]. More recently, Vanscheidt has shown, that Krillase ${ }^{\circledR}$ displays its healing effect at $6 \mathrm{U} / \mathrm{ml}$ [53]. In our study, Krillase $^{\circledR}$ activity remained at a therapeutic level within the same range, even in human wound exudate. At the same time, storage and release from cellulosic hollow fibres as well as the activity of cellulase in the system did not impair enzyme activity.

\section{CONCLUSION}

Medicated wound dressings were prepared by degrading nonwovens of viscose hollow fibres which contain two sets 
of fibres: cellulase-endowed fibres and fibres filled with model drugs, i.e. Krillase ${ }^{\circledR}$ and bacteriophages. Both, fibres and dressings were produced using standardized industrial procedures. Sustained, controlled release of the debriding enzyme Krillase $^{\circledR}$ was demonstrated in vitro, whereas the larger particles of antibiotic Pseudomonas-specific bacteriophages were released instantaneously. Based on this technique, a modular and highly variable drug delivery system suitable for different wounds and wound healing stages could be developed, which has therapeutic value in regard to infection control (antibiosis) and wound bed preparation (debridement). The release kinetics from the medicated web can be controlled by varying the ratio of cellulase- and drugcontaining hollow fibres. The hollow fibre technique can provide a unique solution for the sustained delivery of therapeutic agents from tissue compatible wound dressings.

\section{ACKNOWLEDGEMENT}

The authors thank Dr. Annerose Heller, Institute of Botany, Hohenheim University, Germany, for TEM analysis of bacteriophages. This study was funded by a research grant of the Federal Ministry of Education and Research (BMBFFKZ 0330463 A).

\section{CONFLICT OF INTEREST}

None Declared.

\section{REFERENCES}

[1] Kirsner RS, Eaglstein WH. The wound healing process. Dermatol Clin 1993; 11(4): 629-40.

[2] Percival JN. Classification of wounds and their management. Surgery $2002 ; 20: 114-7$.

[3] Harding KG, Morris HL, Patel GK. Science, medicine and the future: healing chronic wounds. BMJ 2002; 324(7330): 160-3.

[4] Moore K, McCallion R, Searle RJ, Stacey MC, Harding KG. Prediction and monitoring the therapeutic response of chronic dermal wounds. Int Wound J 2006; 3(2): 89-96.

[5] Winter GD, Scales JT. Effect of air drying and dressings on the surface of a wound. Nature 1963; 197: 91-2.

[6] Turner T. Today's products and wound management. Nurs Mirror 1979; 148(25): i-xvi.

[7] Eccleston GM. In Aulton ME, Ed. Pharmaceutics: The science of dosage form design. 3rd edition. UK: Churchill Livingstone 2007; pp. 264-71.

[8] Goldman R. Growth factors and chronic wound healing: past, present, and future. Adv Skin Wound Care 2004; 17(1): 24-35.

[9] Boateng JS, Matthews KH, Stevens HN, Eccleston GM. Wound healing dressings and drug delivery systems: a review. J Pharm Sci 2008; 97(8): 2892-923.

[10] Heenan A. Dressings on the drug tariff. Wales, UK: 1998.

[11] Zavan B, Vindigni V, Vezzu K, et al. Hyaluronan based porous nano-particles enriched with growth factors for the treatment of ulcers: a placebo-controlled study. J Mater Sci Mater Med 2009; 20(1): 235-47.

[12] Imaz I, Rubio-Martinez M, Garcia-Fernandez L, et al. Coordination polymer particles as potential drug delivery systems. Chem Commun (Camb) 2010; 46(26): 4737-9

[13] Bourke SL, Al-Khalili M, Briggs T, Michniak BB, Kohn J, PooleWarren LA. A photo-crosslinked poly(vinyl alcohol) hydrogel growth factor release vehicle for wound healing applications. AAPS PharmSci 2003; 5(4): E33.

[14] Elsner JJ, Zilberman M. Antibiotic-eluting bioresorbable composite fibers for wound healing applications: microstructure, drug delivery and mechanical properties. Acta Biomater 2009; 5(8): 2872-83.

[15] Hellgren L, Mohr V, Vincent J. Proteases of Antarctic krill - a new system for effective enzymatic debridement of necrotic ulcerations. Experientia 1986; 42(4): 403-4.
[16] Mekkes JR, Le Poole IC, Das PK, Kammeyer A, Westerhof W. In vitro tissue-digesting properties of krill enzymes compared with fibrinolysin/DNAse, papain and placebo. Int $\mathrm{J}$ Biochem Cell Biol 1997; 29(4): 703-6.

[17] Chanishvili N, Chanishvili T, Tediashvili M, Barrow PA. Phages and their application against drug-resistant bacteria. J Chem Technol Biot 2001; 76: 689-99.

[18] Kutter B, Raya R, Guttman B, Brabban A, Neitzel J. Lab Procedures. The Evergreen State College 2004.

[19] Ceyssens PJ, Lavigne R, Mattheus W, et al. Genomic analysis of Pseudomonas aeruginosa phages LKD16 and LKA1: establishment of the phiKMV subgroup within the T7 supergroup. J Bacteriol 2006; 188(19): 6924-31.

[20] Erlanger BF, Kokowsky N, Cohen W. The preparation and properties of two new chromogenic substrates of trypsin. Arch Biochem Biophys 1961; 95: 271-8.

[21] Elsner JJ, Berdicevsky I, Zilberman M. In vitro microbial inhibition and cellular response to novel biodegradable composite wound dressings with controlled release of antibiotics. Acta Biomater 2011; 7(1): 325-36.

[22] Kumar TR, Vasantha Bai M, Krishnan LK. A freeze-dried fibrin disc as a biodegradable drug release matrix. Biologicals 2004; 32(1): 49-55.

[23] Lawrence JC. A povidone-iodine medicated dressing. J Wound Care 1998; 7(7): 332-6.

[24] Sawada Y, Ara M, Yotsuyanagi T, Sone K. Treatment of dermal depth burn wounds with an antimicrobial agent-releasing silicone gel sheet. Burns 1990; 16(5): 347-52.

[25] Sawada Y, Ohkubo T, Kudoh M, Sugawara K, Otani K, Sasaki J. An evaluation of a new lactic acid polymer drug delivery system: a preliminary report. Br J Plast Surg 1994; 47(3): 158-61.

[26] Schneider A, Wang XY, Kaplan DL, Garlick JA, Egles C. Biofunctionalized electrospun silk mats as a topical bioactive dressing for accelerated wound healing. Acta Biomater 2009; 5(7): 2570-8.

[27] Gimeno MJ, Garcia-Esteo F, Garcia-Honduvilla N, San Roman J, Bellon JM, Bujan J. A novel controlled drug-delivery system for growth hormone applied to healing skin wounds in diabetic rats. $\mathrm{J}$ Biomater Sci Polym Ed 2003; 14(8): 821-35.

[28] Wallace E. Feeding the wound: nutrition and wound care. $\mathrm{Br} \mathrm{J}$ Nurs 1994; 3(13): 662-7.

[29] Blanchemain N, Haulon S, Martel B, Traisnel M, Morcellet M, Hildebrand HF. Vascular PET prostheses surface modification with cyclodextrin coating: development of a new drug delivery system. Eur J Vasc Endovasc Surg 2005; 29(6): 628-32.

[30] Sripriya R, Kumar MS, Sehgal PK. Improved collagen bilayer dressing for the controlled release of drugs. J Biomed Mater Res B Appl Biomater 2004; 70(2): 389-96.

[31] Wang Y, Wang B, Qiao W, Yin T. A novel controlled release drug delivery system for multiple drugs based on electrospun nanofibers containing nanoparticles. J Pharm Sci 2010; 99(12): 4805-11.

[32] Craig SJ, Shu A, Xu Y, Foong FC, Nordon R. Chimeric protein for selective cell attachment onto cellulosic substrates. Protein Eng Des Sel 2007; 20(5): 235-41.

[33] Comfort AR, Albert E, Langer R. Immobilized enzyme cellulose hollow fibers: II. Kinetic analysis. Biotechnol Bioeng 1989; 34(11): 1374-82.

[34] Comfort AR, Albert EC, Langer R. Immobilized enzyme cellulose hollow fibers: I. Immobilization of heparinase. Biotechnol Bioeng 1989; 34(11): 1366-73.

[35] Comfort AR, Berkowitz S, Albert E, Langer R. Immobilized enzyme cellulose hollow fibers: III. Physical properties and in vitro biocompatibility. Biotechnol Bioeng 1989; 34(11): 1383-90.

[36] Hellgren K. Assessment of Krillase chewing gum for the reduction of gingivitis and dental plaque. J Clin Dent 2009; 20(3): 99-102.

[37] Mann NH. The potential of phages to prevent MRSA infections. Res Microbiol 2008; 159(5): 400-5.

[38] Hohn G, Müller M, Höfer D. Fiber-based approaches for innovative wound care. Proceedings FiberMed 11, International Conference on Fibrous Products in Medical and Health Care, 28-30 June 2011, Tampere, Finland 2011.

[39] Frenning G, Tunon A, Alderborn G. Modelling of drug release from coated granular pellets. J Control Release 2003; $92(1-2)$ : 113 23.

[40] Hancock BC, York P, Rowe RC. The use of solubility parameters in pharmaceutical dosage form design. Int J Pharm 1997; 148: 121. 
[41] Marsac PJ, Shamblin SL, Taylor LS. Theoretical and practical approaches for prediction of drug-polymer miscibility and solubility. Pharm Res 2006; 23(10): 2417-26.

[42] Sheihet L, Piotrowska K, Dubin RA, Kohn J, Devore D. Effect of tyrosine-derived triblock copolymer compositions on nanosphere self-assembly and drug delivery. Biomacromolecules 2007; 8(3): 998-1003.

[43] Soriano I, Evora C. Formulation of calcium phosphates/poly (d,1lactide) blends containing gentamicin for bone implantation. J Control Release 2000; 68(1): 121-34.

[44] Schnieders J, Gbureck U, Thull R, Kissel T. Controlled release of gentamicin from calcium phosphate-poly(lactic acid-co-glycolic acid) composite bone cement. Biomaterials 2006; 27(23): 4239-49.

[45] Wu P, Grainger DW. Drug/device combinations for local drug therapies and infection prophylaxis. Biomaterials 2006; 27(11): 2450-67.

[46] Mekkes JR, Le Poole IC, Das PK, Bos JD, Westerhof W. Efficient debridement of necrotic wounds using proteolytic enzymes derived from Antarctic krill: a double-blind, placebo-controlled study in a standardized animal wound model. Wound Repair Regen 1998; 6(1): 50-7.
[47] Smith F, Dryburgh N, Donaldson J, Mitchell M. Debridement for surgical wounds. Cochrane Database Syst Rev 2011; 5: CD006214.

[48] Singer AJ, McClain SA, Taira BR, Rooney J, Steinhauff N, Rosenberg L. Rapid and selective enzymatic debridement of porcine comb burns with bromelain-derived Debrase: acute-phase preservation of noninjured tissue and zone of stasis. J Burn Care Res 2010; 31(2): 304-9.

[49] Ramundo J, Gray M. Collagenase for enzymatic debridement: a systematic review. J Wound Ostomy Continence Nurs 2009; 36(6 Suppl): S4-11.

[50] Hafezi F, Rad HE, Naghibzadeh B, Nouhi A, Naghibzadeh G. Actinidia deliciosa (kiwifruit), a new drug for enzymatic debridement of acute burn wounds. Burns 2009; 36(3): 352-5.

[51] Schultz G, Mozingo D, Romanelli M, Claxton K. Wound healing and TIME; new concepts and scientific applications. Wound Repair Regen 2005; 13(4 Suppl): S1-11.

[52] Shi L, Ermis R, Kiedaisch B, Carson D. The effect of various wound dressings on the activity of debriding enzymes. Adv Skin Wound Care 2010; 23(10): 456-62.

[53] Vanscheidt W. Krill enzymes in the therapy of chronical wounds. Zeitschrift für Vulnerologie 2007; 1: 10-5.

(C) Hoefer et al.; Licensee Bentham Open.

This is an open access article licensed under the terms of the Creative Commons Attribution Non-Commercial License (http://creativecommons.org/licenses/by-nc/3.0/) which permits unrestricted, non-commercial use, distribution and reproduction in any medium, provided the work is properly cited. 